\title{
Применение секьюритизации денежных потоков в целях финансирования экономического развития
}

\author{
Есин П.Д. ${ }^{19}$
}

В приведенной статье предлагается обоснование основных причин секьюритизации, а также короткий экскурс в историю секьюритизаџии денежных потоков развиваюшимися странами и оценка потенциала развития каждого класса активов. Принимая во внимание заметное увеличение объема денежных переводов, поступающих в развивающиеся страны за последние несколько лет, и опасения, что эти поступления не всегда могут оказать позитивное воздействие на экономики стран-получателей, предлагается рассмотреть роль секьюритизации в усилении эффекта развития экономики в результате денежных переводов. В заключение будут рассмотрень ограничения, сдерживающие эмиссию долга, обеспеченного будущими денежными потоками, а также описана восстановительная роль секьюритизащии для государственной политики.

JEL: F24

Ключевые слова: секьюритизачия, инновачионное финансирование, диверсифицированные права на платежи, международные денежные переводы

\section{Причины секьюритизации}

C позиции инвесторов преимущество секьюритизации будущих денежных потоков заключается в их высоком кредитном рейтинге и их стабильных исторических показателях, как во времена экономических подъемов, так и во времена спадов. В связи с тем что большая часть долговых бумаг торгуется довольно редко, имеет место дефицит адекватной информации относительно цены на вторичном рынке и спреда по таким бумагам. Несмотря на это, доступная информация, а также ощущения игроков этого рынка указывают на то, что средний спред по таким бумагам, как правило, меньше; более того, волатильность как цены таких бумаг, так и спреда по ним ниже, чем по необеспеченным долговым обязательствам развивающихся стран [Ketkar, Ratha, 2009]. Дефолты по облигациям, в основе которых лежат секьюритизированные денежные потоки и которые размещают развивающиеся страны, также происходят довольно редко. В целом класс активов проявил себя весьма неплохо, несмотря на кризис мексиканского песо в 1994-1995 годах, азиатский кризис ликвидности 1997-1998 годов и дефолт по государственным долгам России (1998) и Эквадора (1999).

\section{История секьюритизации будущих денежных потоков}

Развивающиеся страны секьюритизируют будущие поступления на протяжении последних 20 лет. На данный момент три главных рейтинговых агентства (S\&P, Moody's и Fitch) присвоили рейтинги четырехстам подобного рода сделкам. Согласно статистике, собранной агентствами, с помощью этих сделок удалось привлечь финансирование более чем на 80 млрд долл. Самый заметный всплеск эмиссии таких бумаг пришелся на период, последовавший за мексиканским кризисом 1994-1995 годов. В 1996 году объем сделок достиг пиковой отметки в 12 млрд долл., в основном за счет трансакции по секьюритизации поступлений от экспорта нефти мексиканской компанией Ретех (6 млрд долл.). Затем объем сделок оставался на стабильном уровне и составлял в среднем 6,1 млрд долл. в год.

Эмитенты из стран Латинской Америки доминируют на рынке секьюритизации

\footnotetext{
${ }^{19}$ Аспирант кафедры фондового рынка и рынка инвестиций НИУ-ВШЭ.
} 
поступлений. Только на одну Мексику приходится около $30 \%$ всех трансакций с обеспечением в номинальном долларовом выражении. Благодаря стабильной активности бразильских банков по секьюритизации диверсифицированных прав на платежи в начале десятилетия Бразилия переместилась на второе место с долей рынка в 19,3\%. Секьюритизация не является инструментом, доступным исключительно крупным странам. Ряд небольших государств, таких как Сальвадор, Ямайка, Панама и Перу, являются активными участниками рынка секьюритизации денежных переводов и поступлений по кредитным картам. Из эмитентов за пределами Латинской Америки помимо Турции также следует отдельно отметить Египет, Казахстан, Россию и ЮАР.

Несмотря на то что около $32 \%$ от общего объема сделок приходится на секьюритизацию поступлений от экспорта нефти и газа, другие типы обеспечения (такие, как, например, DPR) в последнее время развивались стремительными темпами. Доля сделок, не связанных с продажей нефти, окажется гораздо выше, если в качестве критерия взять не объем, а количество сделок, принимая во внимание серьезное различие в объемах «нефтяных» трансакций по сравнению со всеми остальными. Средний объем сделки, в обеспечении которой лежат поступления от экспорта нефти и газа, составляет 417 млрд долл., в то время как средний объем сделки с другими видами обеспечения существенно ниже (см. табл. 1).

Таблица 1

Глобальный рынок секьюритизации будущих денежных поступлений в разбивке по активам, 1992-2006 гг.

\begin{tabular}{|l|l|l|l|l|}
\hline Источники обеспечения & $\begin{array}{l}\text { Объем } \\
\text { (млн } \\
\text { долл.) }\end{array}$ & $\begin{array}{l}\text { Доля } \\
\mathbf{( \% )}\end{array}$ & $\begin{array}{l}\text { Количеств } \\
\text { о сделок }\end{array}$ & $\begin{array}{l}\text { Средний сделки (млн долл.) } \\
\text { сазмер }\end{array}$ \\
\hline Нефть и газ & 26,250 & 31,3 & 63 & 417 \\
\hline $\begin{array}{l}\text { Диверсифицированные права } \\
\text { (DPR) }\end{array}$ & 23,084 & 27,5 & 122 & 189 \\
\hline Денежные переводы & 1,782 & 2,1 & 16 & 111 \\
\hline Платежи по кредитным картам & 13,044 & 15,6 & 63 & 207 \\
\hline Минералы и металлы & 9,164 & 10,9 & 55 & 167 \\
\hline Сельскохозяйственные товары & 2,705 & 3,2 & 22 & 123 \\
\hline Продажи авиабилетов & 1,486 & 1,8 & 8 & 187 \\
\hline Услуги мобильной связи & 1,310 & 1,6 & 15 & 87 \\
\hline Другие & 4,978 & 5,9 & 23 & 216 \\
\hline Всего & 83,803 & 100 & 387 & 212 \\
\hline
\end{tabular}

Источник: Fitch Ratings, Moody's and Standard \& Poor's

\section{Потенциал сделок по секьюритизации будущих поступлений}

Сделки по секьюритизации будущих поступлений позволяют эмитентам использовать денежные потоки в качестве залога на протяжении нескольких лет и таким образом получить возможность привлечения средств с рынка капиталов в объеме, в разы превышающем планируемые поступления за отдельно взятый год. Для того чтобы оценить потенциал этих сделок, необходимо получить критерий или базу для сравнения, с помощью которой можно измерить жесткость ограничений, накладываемых на выпуск таких ценных бумаг.

Наиболее реалистичную оценку потенциала секьюритизации отражает таблица 2. Представленная в ней статистика основана на вышеупомянутой предпосылке о том, что наибольшую пользу секьюритизация приносит в случае, если трансакция страны с суверенным кредитным рейтингом ниже среднего уровня, получает рейтинг инвестиционного уровня. Соответственно, основными кандидатами на проведение секьюритизации являются страны с рейтингом В и выше, но ниже инвестиционного уровня, 
поскольку использование будущих поступлений в качестве закладной позволяет трансакции получить рейтинг до 5 ступеней выше суверенного кредитного уровня. Сужение круга стран на основании этого критерия предполагает суммарный потенциал эмиссии в районе 57 млрд долл. в год.

Таблица 2

Уточненный потенциал сделок по секьюритизации будущих денежных поступлений в разбивке по регионам и секторам в среднем за период 2003-2006 гг. (млрд долл.)

\begin{tabular}{|c|c|c|c|c|c|}
\hline Страна/регион & $\begin{array}{c}\text { Экспорт } \\
\text { нефти и } \\
\text { газа }\end{array}$ & $\begin{array}{c}\text { Экспорт } \\
\text { с/x } \\
\text { товаров }\end{array}$ & $\begin{array}{c}\text { Экспорт } \\
\text { минералов } \\
\text { и металлов }\end{array}$ & $\begin{array}{c}\text { Поступления } \\
\text { по кредитным } \\
\text { картам }\end{array}$ & Всего \\
\hline Все развивающиеся страны & 35,1 & 4,2 & 9,2 & 8,5 & 57,0 \\
\hline Страны с низким доходом & 4,4 & 1,0 & 1,9 & 1,2 & 8,5 \\
\hline $\begin{array}{l}\text { Страны с доходами ниже } \\
\text { среднего }\end{array}$ & 19,0 & 1,9 & 0,9 & 3,5 & 25,3 \\
\hline $\begin{array}{l}\text { Страны с доходами выше } \\
\text { среднего }\end{array}$ & 11,7 & 1,3 & 4,3 & 3,8 & 21,1 \\
\hline $\begin{array}{lcc}\text { Восточная } & \text { Азия } & \text { и } \\
\text { Тихоокеанский регион } & \end{array}$ & 5,7 & 1,1 & 1,1 & 5,4 & 13,3 \\
\hline Европа и Центральная Азия & 2,8 & 0,4 & 0,5 & 5,0 & 8,5 \\
\hline $\begin{array}{l}\text { Латинская Америка } \\
\text { Карибский бассейн }\end{array}$ & 13,7 & 1,5 & 4,3 & 3,3 & 22,7 \\
\hline $\begin{array}{l}\text { Ближний } \quad \text { Восток } \\
\text { Северная Африка }\end{array}$ & 10,3 & 0,2 & 0,5 & 2,2 & 13,2 \\
\hline Южная Азия & 1,6 & 0,3 & 1,1 & 0,9 & 3,9 \\
\hline Африка южнее Сахары & 1,0 & 0,8 & 0,5 & 1,3 & 2,2 \\
\hline
\end{tabular}

Источник: Оценки экспертов Всемирного Банка, данные по экспорту из отчетов Всемирного Банка World Development Indicators за разные годы

Таблица подтверждает гипотезу о том, что доминирующим источником потенциальной секьюритизации среди всех классов активов и в общей сумме по регионам остаются экспортные поступления от продаж нефти и газа. Они составляют более $60 \%$ всех эмиссий развивающимися странами. Потенциал для развития секьюритизации минералов и металлов относительно высок для стран с доходами выше среднего, в частности в Латинской Америке и на Карибах, а также в Южной Азии. Напротив, потенциал развития секьюритизации платежей по кредитным картам относительно выше для стран с доходами ниже среднего, в основном из Южно-Азиатского региона.

В целом объем будущих поступлений из развивающихся стран от экспорта всего спектра активов может достигать 150 млрд долл., однако наиболее реалистичная оценка всетаки составляет 57 млрд долл. в год. Интересно, что регион Латинской Америки составляет от четверти до половины этого потенциального объема, что серьезно отличается от текущей ситуации, при которой регион доминирует по объемам эмиссии, не принимая во внимание Европу и Центральную Азию. Однако это наблюдение не предполагает, что потенциал для секьюритизации в Латино-Американском регионе исчерпан. Несложные статистические выкладки позволяют сделать вывод о серьезном потенциале секьюритизации поступлений в других регионах, в частности в Восточной Азии и Тихоокеанском регионе, на Ближнем Востоке и в Северной Африке. Многие страны из названных регионов представляют собой страны со средним уровнем доходов и нуждаются во внешнем финансировании. Некоторые ближневосточные страны имеют достаточно большие объемы обеспечения в виде запасов нефти, которые потенциально могут быть секьюритизированы, если данные страны будут 
остро нуждаться во внешнем капитале. То же самое относится и к странам Восточной Азии и Тихоокеанского региона (Индонезия, Малайзия, Филиппины). В Южной Азии основными драйверами развития секьюритизации будущих денежных поступлений, скорее всего, будут денежные потоки от экспорта металлов и минералов и от «туристических» платежей по кредитным картам.

Что касается России, то выбор актива, лежащего в обеспечении подобных трансакций, для нашей страны очевиден. Как известно, Россия все еще остается во многом сырьевой экономикой, изменение ВВП имеет ярко выраженную корреляцию с ценами на основные экспортные ресурсы: нефть и газ. Первой сделкой в России и странах СНГ по секьюритизации будущих денежных потоков, которая была отрейтингована S\&P в 2001 году, была сделка по секьюритизации поступлений от экспорта газа «Газпромом» (2004). «Газпром» продавал газ, у него были и есть долгосрочные контракты на поставку газа в страны Европы, эти контракты очень длинные, соответственно, компания была уверена в том, что деньги будут поступать по этим контрактам еще долгое время. Таким образом, «Газпром» фактически переуступил права требования по этим будущим потокам в пользу инвесторов. Впоследствии, в октябре 2004 года, «Росбанком» был осуществлен первый среди российских банков секьюритизированный выпуск еврооблигаций. «Росбанк» осуществил секьюритизацию потоков от VISA и MasterCard, поступающих в погашение задолженности платежных систем перед «Росбанком». Данная задолженность формируется в результате осуществления «Росбанком» авансовых расчетов с торговыми и сервисными предприятиями, в которых оплата производилась с помощью пластиковых карт VISA и MasterCard. Это был первый в российской практике случай присвоения рейтинговыми агентствами Moody's и Fitch рейтинга выпуска выше рейтинга банка-инициатора по обязательствам в национальной валюте. Рейтинг банка на тот момент был на уровне В1 (Moody's) и B (Fitch), а сделке были присвоены рейтинги $\mathrm{Ba} 3$ и $\mathrm{B}+$ соответственно. Объем выпуска на Люксембургской фондовой бирже составил 300 млн долл., из них 225 млн было привлечено во время первой эмиссии в октябре 2004 года, еще 75 млн - во время дополнительной эмиссии в феврале 2005 года. Доходность при размещении составила 9,75\%.

\section{Ускорение эффекта экономического развития за счет трансграничных денежных переводов}

В последние годы благодаря активной трудовой миграции значительно возросли объемы денежных переводов из развитых в развивающиеся страны. Для сравнения: в 2000 году этот показатель был на уровне 84,5 млрд долл., тогда как уже к 2007 году он увеличился до 240 млрд долл. (по данным Всемирного Банка). Несмотря на существенную роль трансграничных денежных переводов в сокращении бедности и поддержке инвестиций в человеческий капитал, невозможно однозначно судить о влиянии этого фактора на экономическое развитие [Chami, Fullencamp, 2003]. В то время как тезис о том, что денежные переводы приводят к замедлению роста, наталкивается на ряд теоретических и эмпирических несоответствий, практически нет сомнений в том, что развивающиеся страны могут предпринять действия, направленные на эффективное использование подобных переводов. Банки могут получить финансирование через секьюритизацию поступлений от денежных переводов для их последующего использования с целью расширения кредитования.

Посредством нейтрализации риска конвертируемости валюты, представляющим основной компонент суверенного риска, структура секьюритизации будущих денежных поступлений позволяет полученным ценным бумагам иметь более высокий рейтинг, чем суверенный кредитный рейтинг. Тем не менее, как уже отмечалось ранее, рейтинги таких сделок все равно ограничены кредитным рейтингом эмитента в национальной валюте. В этом смысле у банков есть определенное преимущество. В частности, крупные национальные банки с высокой рыночной долей на внутреннем рынке, как правило, получают рейтинги инвестиционного уровня в национальной валюте. Государства не могут 
допустить их банкротства, опасаясь распространения системного волнового эффекта. До тех пор, пока крупные банки имеют стимулы «оставаться на плаву», вероятнее всего, они будут продолжать получать денежные переводы работающих мигрантов и соответственно сохранять способность обслуживать свои секьюритизованные обязательства. Таким образом, крупные банки могут использовать данный структурированный финансовый продукт для получения рейтингов инвестиционного класса по своим долгам в иностранной валюте, обеспеченным денежными переводами из-за рубежа. К примеру, в случае с Сальвадором ценным бумагам был присвоен рейтинг инвестиционного класса на целых 4 ступени выше их суверенного рейтинга субинвестиционного класса ВВ. Нижеприведенная таблица 3 иллюстрирует разницу между рейтингом сделки и соответственным суверенным рейтингом.

Таблица 3

Рейтинги сделок по секьюритизации будущих поступлений от денежных переводов и диверсифицированных прав на платежи

\begin{tabular}{|l|l|l|l|l|l|}
\hline Год & \multicolumn{1}{|c|}{ Эмитент } & $\begin{array}{c}\text { Объем } \\
\text { сделки } \\
\text { (млн. \$) }\end{array}$ & $\begin{array}{l}\text { Рейтинг } \\
\text { сделки }\end{array}$ & $\begin{array}{c}\text { Суверенный } \\
\text { рейтинг }\end{array}$ & $\begin{array}{l}\text { Прибавка в } \\
\text { рейтинге (n } \\
\text { ступеней) }\end{array}$ \\
\hline 2007 & Banco Bradesco (Бразилия) & 400 & $\mathrm{~A}-$ & $\mathrm{BB}$ & 5 \\
\hline 2005 & Banco de Credito del Peru & 50 & $\mathrm{BBB}$ & $\mathrm{BB}+$ & 2 \\
\hline 2004 & Banco Salvadoreno & 25 & $\mathrm{BBB}$ & $\mathrm{BB}+$ & 2 \\
\hline 2002 & Banco do Brasil & 250 & $\mathrm{BBB}+$ & $\mathrm{BB}-$ & 5 \\
\hline 1998 & Banco Cuscatlan (Сальвадор) & 50 & $\mathrm{BBB}$ & $\mathrm{BB}$ & 3 \\
\hline
\end{tabular}

Ряд скептически настроенных исследователей ставят под сомнение предпосылку о стабильности переводов, а также стимулов, которые государства могут использовать для изменения направления этих платежей от банков, применяющих секьюритизацию, к иным посредникам (возможно, государственным) и на другие цели. Кроме того, открытым остается вопрос о возможностях банков секьюритизировать формально не принадлежащие им денежные переводы.

\section{Ограничения сделок по секьюритизации и их роль в государственной политике}

Оцененный потенциал сделок по секьюритизации позволяет сделать вывод, что развивающиеся страны имеют широкий набор вариантов привлечения значительного объема финансирования за счет секьюритизации будущих поступлений. Тем не менее фактический объем эмиссий данного типа долга относительно невелик.

Принимая во внимание тот факт, что рейтинг сделки ограничен кредитным рейтингом эмитента в национальной валюте, наиболее вероятными кандидатами на эмиссию такого типа долга можно считать эмитентов инвестиционного класса (в национальной валюте) из стран с суверенным рейтингом ниже инвестиционного уровня. Тем не менее малое количество компаний с рейтингом инвестиционного класса в странах с более низким суверенным рейтингом ограничивает возможности развивающихся стран производить эмиссию секьюритизированного долга. В такой ситуации банки имеют преимущество. Большинство правительств вряд ли позволит системообразующим банкам обанкротиться. Такие предпочтения правительств приводят к тому, что банки спокойно продолжают функционировать, что позволяет им в свою очередь продолжать генерировать денежные переводы работников.

Несмотря на то что эмитенты с рейтингом инвестиционного класса из стран с низким суверенным рейтингом считаются наиболее заинтересованными в проведении таких сделок, чрезвычайно важно, чтобы страна эмитента предоставляла определенную институциональную и юридическую защиту. В целом стоит отметить, что довольно сложно структурировать сделку по секьюритизации в странах, имеющих ограниченную 
законодательную базу по этому направлению. Обычно скудость законов предполагает более высокую степень неопределенности, что серьезно усложняет структурирование сделки. Закон о банкротстве, в частности, является ключевым для трансакций по секьюритизации. В идеале закон о банкротстве должен предусматривать возможность «действительной продажи» (true sale) будущих потоков. Однако возможно структурировать трансакцию по секьюритизации, изучив историю приверженности страны существующим законам или определить степень строгости закона по отношению к возможности принятия принципа «действительной продажи».

Другим существенным ограничением эмиссии являются длинные сроки ее реализации и очень специфические навыки, необходимые для соединения в единое целое структур, обеспечивающих защиту от различных элементов риска и позволяющих рейтинговым агентствам присваивать этим облигациям рейтинги выше «суверенного потолка». Длительность реализации (от 6 месяцев до года) удерживала инвестиционные банки от агрессивного наращивания количества этих сделок. Кроме того, специальные навыки, необходимые для структурирования таких сделок, вместе с длинными сроками их реализации предполагали, что стимулировать этот бизнес обходится довольно дорого для инвестиционных банков и для эмитентов, на кого в первую очередь и будут переложены эти затраты. Юридические затраты по структурированию таких сделок непомерно высоки, обычно от 2 до 3 млн долл. за трансакцию. Более того, эти издержки фиксированы. Так, эмиссии, обеспеченные будущими поступлениями, стали доступны только в случае привлечения достаточно больших объемов финансирования. Соответственно, только крупные эмитенты, которые способны обосновать привлечение серьезных финансовых ресурсов на международных рынках капитала, рассматриваются в качестве потенциальных заемщиков для этого класса активов. Ограниченное число таких компаний в развивающихся странах, таким образом, явилось еще одним препятствием развития этого класса.

В последние годы вышеупомянутые ограничения стали существенно менее значимыми благодаря накопленному опыту, полученному эмитентами и инвестиционными банками. Теперь международные инвестиционные банки имеют возможность структурировать сделки по секьюритизации будущих потоков в очень сжатые сроки.

Отсутствие надлежащей юридической инфраструктуры представляет собой еще одно ограничение для таких сделок. Вдобавок к отсутствию соответствующих юридических структур наблюдаются разногласия в развивающихся странах и в международных финансовых институтах относительно классификации и отражения этих сделок в бухгалтерской отчетности. Ключевой закон - закон о банкротстве. При этом исключительно важно, чтобы закон о банкротстве позволял заложенным активам сохраняться в том же качестве в случае дефолта, что, собственно, и отражает принцип «действительной продажи». Помимо закона о банкротстве развивающиеся страны должны следовать принципу «больше - лучше» в отношении количества юридических актов и норм, поскольку их ограниченное число означает более высокую степень неопределенности и повышенную стоимость структурирования.

В свою очередь международные финансовые институты могут играть существенную роль в стимулировании развития данного класса активов. Всемирный Банк или Международная Финансовая Корпорация (МФК), например, могут предоставлять кредитную поддержку, повышая степень надежности [Corbi, 2009]. Такого рода обеспечение может быть в форме «кредитной оболочки» наподобие той, которую предоставляют страховые компании при коммерческих сделках. В подобных трансакциях транши с низким рейтингом повышаются до уровня траншей высокого рейтинга в результате гарантии со стороны кредитного агента. Поскольку сделка может быть структурирована с использованием различных траншей, Всемирный Банк может принимать участие в формировании старшего, среднего или младшего траншей в зависимости от волатильности риска и своих собственных целей. Очевидно, что Всемирный Банк преследует следующие конечные цели:

1. Облегчить доступ к финансированию для институтов с низким рейтингом и не 
имеющих рейтинга.

2. Ослабить асимметрию международного финансового рынка и снизить ограничения для новых эмитентов из развивающихся стран.

МФК может стимулировать рост секьюритизации денежных переводов путем предоставления прямых и косвенных гарантий. Прямая гарантия в отношении структурированной сделки может представлять собой соглашение о разделе риска между посредником и Всемирным Банком, которое позволяет ограничить максимальные потери $50 \%$ транша. Соглашение о разделе риска может также быть заключено на условиях обеспечения в равной мере, что ограничивает риски в случае банкротства оригинатора, сокращая максимальную степень подверженности риску дефолта и улучшая, таким образом, скорость возврата средств Всемирного Банка. Косвенная гарантия имеет место в том случае, если Всемирный Банк предоставляет встречную гарантию другим посредникам, предоставляющим гарантии держателям облигаций. Наконец, Всемирный Банк может быть задействован путем предоставления им кредитно-дефолтного свопа или эквивалентного финансового инструмента для повышения рейтинга сделки. Любое участие Всемирного Банка в сделке приводит как минимум к двум преимуществам для инвесторов. Во-первых, соответствующие транши получают рейтинг ААА. Во-вторых, участие Всемирного Банка позволяет уменьшить регулятивные требования к минимальной величине капитала для любых инвесторов банка. Требования по достаточности капитала по Базелю II - 0\%, в противном случае они составляют все $100 \%$.

Наконец, МФК, так же как и Всемирный Банк, может взять на себя весьма полезную функцию по обучению чиновников из государственного сектора и менеджеров из частного сектора из развивающихся стран той роли, которую может играть данный класс активов в кризисные времена, и тому, каким образом можно оптимально определить и структурировать сделки по секьюритизации, обеспеченные денежными поступлениями в будущем.

\section{Заключение}

К настоящему моменту секьюритизация денежных потоков в РФ осуществлялась в основном крупными банками (Росбанк, ХКФ Банк, «Русский Стандарт»). Первичными активами послужили платежи по кредитным картам, потребительские кредиты, а также лизинговые платежи (сделка Red Arrow). Проведенные сделки отличаются разнообразием форм структурирования. Российские оригинаторы представляют различные секторы экономики.

Очевидно, что РФ необходимо предпринимать дальнейшие шаги для развития института секьюритизации, и прежде всего следует сконцентрировать усилия на достижении необходимого качества институциональной среды. Учитывая современные тенденции на финансовых рынках, следует отметить, что недостаточно будет обойтись принятием в рабочем порядке временных мер - необходима комплексная концепция. Есть определенные признаки того, что российские законодательные органы приходят к пониманию этого постулата, но в целом проблемы и многочисленные несовершенства российской экономики по-прежнему настолько глубоки, что без решения части наиболее критических из них будут невозможны серьезные позитивные изменения в более узкоспециализированных сферах, одной из которых как раз и является секьюритизация денежных поступлений. В связи с этим можно предположить, что при внесении необходимых изменений и дополнений в действующее законодательство секьюритизация активов и генерируемых ими денежных потоков в перспективе претендует на ведущие позиции в арсенале инструментов финансирования российских компаний.

В развитых экономиках секьюритизация обычно рассматривается как эффективный инструмент финансирования корпоративного, а также государственного сектора. Тем не менее не стоит забывать о том, что число скептически настроенных по отношению к этой технике значительно возросло за последние несколько лет, во многом из-за сканадально 
известных американских ипотечных облигаций типа «subprime», поэтому крайне важно избегать повторения чужих ошибок и стараться создавать в своей стране максимально прозрачные механизмы и ограничения, постоянно проверяя созданную институциональную систему на устойчивость и жизнеспособность. Фактически одними из основных ограничений при использовании рассматриваемой техники рефинансирования компаниями служат финансовый оборот организации и потребность в капитале. Это подтверждается успешным опытом проведения сделок секьюритизации за рубежом и значительным ростом спроса на данный тип рефинансирования у российских оригинаторов, в частности в 2006-2008 годах.

Применительно к России секьюритизация поступлений от продажи нефти на международных сырьевых рынках может рассматриваться как один из возможных инструментов привлечения финансовых ресурсов в экономику страны, при этом довольно перспективным в долгосрочном плане. В случае эффективного управления этими поступлениями они вполне могут быть использованы для решения задач модернизации экономики.

\section{Список литературы}

1. Сборник статей «Ипотечное кредитование и секьюритизация» совместный проект компании «РУСИПОТЕКА» и журнала «Рынок ценных бумаг»), 2007.

2. Ketkar, S.. Ratha, D. (2009), Innovative financing for development (Future-Flow Securitisation for Development Finance), Washington DC: World Bank, p. 17-18.

3. Chami, R., Fullenkamp, C., and Jahjah, S. (2003), Are Immigrant Remmitance Flows a Source of Capital for Development? - Washington DC: IMF Working Paper No. 03/189, International Monetary Fund, 2003.

4. Corbi, A. (2009), Securitisation of Future Flow Assets: Diversified Payments and Workers' Remittances. - Washington DC: Working Paper, Economic Policy and Prospects Group, World Bank, 2009.

5. Future Flow Securitization Rating Methodology (2006). International Criteria Report, February 15, 2006. http://www.fitchratings.com.

6. Ketkar, S., and Ratha, D. (2001), Development Financing during a Crisis: Securitization of Future Receivables. - Washington DC: Policy Research Working Paper 2582, World Bank, 2001a.

7. Ratha, D. (2006), Leveraging Remittances for International Capital Market Access.Washington DC: Mimeo. Development Prospects Group, World Bank, 2006. 